\title{
Spectrum of DHCR7 mutations in Slovak patients with Smith-Lemli-Opitz syndrome and detection of common mutations by PCR-based assays
}

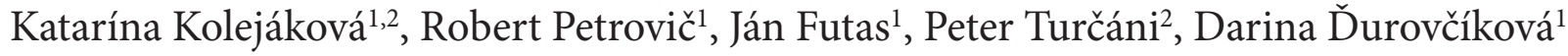 \\ and Ján Chandoga ${ }^{1}$ \\ ${ }^{1}$ Centre of Medical Genetics, University Hospital Bratislava, Slovakia \\ ${ }^{2} 1^{\text {st }}$ Department of Neurology, Medical faculty of Comenius University and University Hospital, Bratislava, Slovakia
}

\begin{abstract}
The Smith-Lemli-Opitz syndrome (SLOS), an autosomal recessive disorder associated with multiple developmental malformations, is caused by a large spectrum of mutations in the DHCR7 gene. Mutations in the DHCR7 gene lead to a 7-dehydrocholesterol reductase deficiency, which is the final enzyme in the pathway of the cholesterol biosynthesis. Reduced cholesterol levels and elevated concentrations of its precursor 7-dehydrocholesterol in plasma and tissues are the major biochemical hallmarks of this disorder. In all patients a biochemical analysis of blood sterols using the gas chromatography/mass spectrometry was performed to confirm the clinical diagnosis of SLOS. We have also determined the mutational spectrum of DHCR7 gene in 17 Slovak patients. We identified six different mutations: nonsense mutation W151X and missense mutations V326L, L109P, G410S, R352Q, Y432C. Mutations W151X and V326L accounted for 76\% of the SLOS alleles in Slovak population. The Slovak mutational spectrum is similar to that observed in other Central European countries. We also report simple polymerase chain reaction (PCR)-based assays that allow efficient and rapid mutation analysis.
\end{abstract}

Key words: Smith-Lemli-Opitz syndrome -7 -dehydrocholesterol - DHCR7 gene - DHCR7 mutation analysis - Slovak patients

\section{Introduction}

The Smith-Lemli-Opitz syndrome (SLOS, MIM 270400) is an autosomal recessive disorder of sterol metabolism characterised by multiple congenital anomalies and dysmorphic features. The clinical spectrum includes microcephaly, cleft palate, ptosis, syndactyly of the second and third toes, postaxial polydactyly, anomalies of heart, gastrointestinal tract and genitourinary system. Failure to thrive, behavioral problems and mental retardation are the most typical hallmarks of the disorder (Opitz 1994; Cunniff et al. 1997; Kelley 1998; Opitz 1999; Kelley and Hennekam 2000; Nowaczyk and Waye 2001; Witsch-Baumgartner et al. 2001a,b). The clinical phenotype of SLOS patients is extremely variable ranging from

Correspondence to: Katarína Kolejáková, Centre of Medical Genetics, University Hospital, Mickiewiczova 13, 81369 Bratislava, Slovakia

E-mail:katekole@centrum.sk life-threatening congenital anomalies and severe mental retardation to mild physical malformations and moderate mental impairment.

The incidence of SLOS, based on elevated 7-dehydrocholesterol (7DHC) levels, is estimated to range from $1: 60,000$ to $1: 10,000$ of live births worldwide. SLOS seems to be more prevalent among peoples of Caucasian origin and are rare among Asian and African populations. The frequency of SLOS in European populations is estimated from $1: 40,000$ to $1: 15,000$ (Kelley 1998; Opitz 1999; Kelley and Hennekam 2000). In Ontario, Canada SLOS has an incidence of $1: 29,700$ in Caucasians, while in the UK and the USA, the incidence is estimated as $1: 60,000$ (Ryan et al. 1998; Nowaczyk et al. 2001). It seems to be that SLOS is the most frequent in Central Europe (1: 10,000 in Czech Republic) (Kozák et al. 2000).

The causative factor of the SLOS is a deficiency of 7DHC reductase (DHCR7, E.C. 1.3.1.21), which catalyses the NADPH-dependent reduction of the C7-8 double bond of 
7DHC to produce cholesterol in the last step of KandutschRussel pathway of cholesterol biosynthesis (Irons et al. 1993; Tint et al. 1994). Consequently, the reduced enzyme activity leads to low plasma and tissue concentrations of cholesterol and to elevated levels of sterol precursors, 7DHC and 8DHC (Tint et al. 1995).

In 1998 the human 7DHC reductase gene (DHCR7 gene, Genbank accession number NC 000011) was identified and mapped to chromosome 11q12-13 (Fitzky et al. 1998; Moebius et al. 1998; Wassif et al. 1998; Waterham et al. 1998). The human DHCR7 gene spans 14,100 bp (base pairs) of genomic DNA, consisting of nine exons and eight introns. The first two exons are non-coding and the start codon is located in exon 3 . The DHCR7 mRNA has an open reading frame of $1425 \mathrm{bp}$, encoding for a polypeptide of 475 amino acids. The human DHCR7 is an integral membrane protein with a calculated molecular weight of $54.5 \mathrm{kDa}$. Although the exact transmembrane topology of DHCR7 has not been experimentally determined, some models have been proposed based on the predicted amino acids sequence. Fitzky et al. (1998) proposed the model with nine transmembrane spanning domains, when $\mathrm{N}$-terminus is oriented towards the cytosol and the C-terminus is predicted to be within the lumen of the endoplasmic reticulum. The DHCR7 mRNA is expressed ubiquitously with the highest expression in the adrenal glands, liver, testis and brain (Moebius et al. 1998).

Up to now 121 different mutations in the DHCR7 gene have been published. Missense mutations are the most common (Cardoso et al. 2005; Correa-Cerro and Porter 2005; Witsch-Baumgartner et al. 2005; Yu and Patel 2005) and have been classified according to the predicted domains of DHCR7: transmembrane domains, the $4^{\text {th }}$ cytoplasmic loop, C-terminus (Witsch-Baumgartner et al. 2001a).

In the present study we report biochemical and molecular analysis of 17 Slovak patients with SLOS. Biochemical diagnosis of sterols (cholesterol, 7DHC and 8DHC) was performed by gas chromatography/mass spectrometry (GC/ MS). Automated sequencing of coding region of DHCR7 gene was used to identify the spectrum of mutations. To facilitate mutation analysis we developed rapid polymerase chain reaction (PCR)-based assays for common SLOS mutations found in Slovak patients.

\section{Materials and Methods}

\section{Samples}

Samples were submitted to our clinical laboratory to confirm existing or tentative diagnosis of SLOS or to evaluate an ambiguous phenotype. Over a period of 12 years, we have diagnosed 17 patients with clinical features of SLOS. Each patient underwent a thorough clinical examination, a biochemical analysis of sterols and mutation analysis of DHCR7 gene.

Plasma/serum samples were collected without regard to state of fasting and kept frozen at $-20^{\circ} \mathrm{C}$ until sterol analysis. DNA extraction was performed from blood samples collected into tubes with EDTA. Isolated genomic DNA was stored at $4^{\circ} \mathrm{C}$ or $-70^{\circ} \mathrm{C}$ prior to DNA analysis.

\section{Biochemical analysis}

Total plasma/serum cholesterol and 7DHC were quantified by GC/MS and concentration of cholesterol was also determined by cholesterol oxidase test (Bio-Lachema test).

The GC/MS method for extraction of neutral sterols was adapted form Kelley (1995). Briefly, plasma were mixed with 5- $\alpha$-cholestane (internal standard) and saponified with $\mathrm{KOH}$. After saponification the samples were extracted by hexane by vortexing. The pooled hexane extracts were dried under a stream of nitrogen and derivatized with bistrifluoroacetamide and pyridine. Sterol analysis was preformed on a Finnigan MAT GCQ gas chromatographmass spectrometer.

\section{Molecular analysis}

Amplification: Genomic DNA was extracted from peripheral blood leukocytes using a commercially available kit (QIAamp DNA Mini Kit, QIAGEN). Exon 3-9 and their flanking sequences were amplified using the polymerase chain reaction. The amplification primers were described previously (Fitzky et al. 1998). The reaction mixture contained 100-150 ng genomic DNA, $200 \mu \mathrm{mol} / \mathrm{l}$ dNTPs, 0.3 $\mu \mathrm{mol} / \mathrm{l}$ of each primer, 1 U DNA polymerase DyNAzyme (Finnzymes) in a final volume of $50 \mu \mathrm{l}$. The amplification conditions were: initial denaturation at $95^{\circ} \mathrm{C}$ for $5 \mathrm{~min}, 30$ cycles of PCR with each cycle consisting of denaturation for $30 \mathrm{~s}$ at $95^{\circ} \mathrm{C}$, annealing for $30 \mathrm{~s}$ at $65^{\circ} \mathrm{C}$, extension for $30 \mathrm{~s}$ at $72^{\circ} \mathrm{C}$ and the final extension for $10 \mathrm{~min}$ at $72^{\circ} \mathrm{C}$. Ten microliters of the PCR products were run on $2 \%$ agarose gel to verify the amplification. Then, the remaining part of PCR product was purified with ethanol precipitation and quantified using Mass Ruler (Fermentas).

Sequencing: The complete coding region of gene was sequenced on the ABI Prism 310 Genetic Analyzer using ABI Prism Big Dye Terminator v3.1 Cycle Sequencing Ready Reaction Kit (Applied Biosystems).

Restriction analysis: PCR-restriction fragment length polymorphism (RFLP) was used to detect mutations W151X and Y432C. AluI digestion of exon 6 and HpyCH4V digestion of exon $9 \mathrm{~b}$ were performed using $20 \mu \mathrm{l}$ of PCR product, $5 \mathrm{U}$ of restriction enzyme and were incubated at $37^{\circ} \mathrm{C}$ overnight. The AluI restriction fragments were separated by $2 \%$ agarose gel electrophoresis and $\mathrm{HpyCH} 4 \mathrm{~V}$ restriction 
fragments were separated by $3 \%$ Metaphor agarose (Lonza) gel electrophoresis (Table 1).

Allele specific assays: Based on the amplification refractory mutation system (ARMS), test was designed to detect mutations V326L and L109P. Each ARMS assay uses two sets of primers: one set that amplifies intragenic DHCR7 region, which serves as a positive internal control of PCR amplification and the other set of primers for allele-specific amplification. ARMS test for each patient consists of two reactions. V326L ARMS assay: First reaction contains control primers (3F and 3R) and primers for amplification of wild type allele (9F and 9Rwt), if it is present, and the second one contains control primers and primers for amplification of mutant allele (9F and 9Rmut), if it is present. L109P ARMS assay: First reaction uses primers $5 \mathrm{R}, 5 \mathrm{~F}$ and $5 \mathrm{Fwt}$. The second one uses primers $5 \mathrm{R}, 5 \mathrm{~F}, 5 \mathrm{Fmut}$. $5 \mathrm{R}$ and $5 \mathrm{~F}$ primers represent an internal control and primers 5Fwt and 5Fmut are allele specific. For each ARMS assay, PCR was carried out in a reaction volume of $25 \mu \mathrm{l}$ containing $100 \mathrm{ng}$ of genomic DNA, $200 \mu \mathrm{mol} / \mathrm{l}$ dNTPs, $2 \mathrm{mmol} / 1 \mathrm{MgCl}_{2}$, 1 U DNA polymerase DyNAzyme (Finnzymes). For V326L ARMS assay $0.3 \mu \mathrm{mol} / \mathrm{l}$ of forward (3F) and reverse (3R) control primers and $0.24 \mu \mathrm{mol} / \mathrm{l}$ of each primer for allele specific amplification (9F, 9Rwt, 9Rmut) were used. For L109P ARMS assay $0.36 \mu \mathrm{mol} / \mathrm{l}$ of primer $5 \mathrm{R}$ and $0.18 \mu \mathrm{mol} / \mathrm{l}$ of primers 5F, 5Fwt, 5Fmut were used. Tempera- ture cycling conditions were: initial denaturation at $95^{\circ} \mathrm{C}$ for 5 min, followed by 35 cycles of $45 \mathrm{~s}$ at $95^{\circ} \mathrm{C}$, annealing for $45 \mathrm{~s}$ at $68^{\circ} \mathrm{C}$, extension for $45 \mathrm{~s}$ at $72^{\circ} \mathrm{C}$ and the last extension for 10 min at $72^{\circ} \mathrm{C}$. PCR products were analysed by electrophoresis in $2 \%$ agarose gel, stained with ethidium bromide and visualised under UV light (Table 2).

\section{Results}

\section{Patients}

In 17 unrelated Slovak patients, the clinical diagnosis of SLOS was confirmed by biochemical and mutation analysis. There were no consanguineous marriages in families of SLOS patients. The diagnosis of SLOS was made between age of one day and 14 years. The patients included 9 females (46, $\mathrm{XX}$ ) and 8 males $(46, \mathrm{XY})$. The phenotypic spectrum ranged from very mild to lethal cases (10 patients with severe SLOS died in newborn period) (Table 3).

\section{Biochemical analysis}

For measurement of total cholesterol level in serum a routine biochemical oxidase based test and GC/MS method were

Table 1. Detailed description of PCR-RFLP assays for mutations W151X and Y432C

\begin{tabular}{|l|l|l|}
\hline Mutation & W151X & Y432C \\
\hline Primers $\left(5^{\prime} \rightarrow 3^{\prime}\right)$ & 6F & 9bF \\
& GTTGGGAAAGCGCCTTCATTT & CACAGCAAGCTGCTGGTGTCGGG \\
& 6R & 9bR \\
& GGATTCTCAGTGCTCAGGGCT & TGGCAGAACACGCTCTTGACAGC \\
\hline Restriction enzyme & AluI & HpyCh4V \\
\hline Restriction fragment sizes & Mutant: $282 \mathrm{bp}+80 \mathrm{bp}$ & Mutant: $185 \mathrm{bp}+125 \mathrm{bp}$ \\
& Wild type: $362 \mathrm{bp}$ & Wild type: $310 \mathrm{bp}$ \\
\hline
\end{tabular}

Table 2. Detailed description of ARMS assays for mutations V326L and L109P

\begin{tabular}{|l|l|l|}
\hline Mutation & V326L & L109P \\
\hline Primers $\left(5^{\prime} \rightarrow 3^{\prime}\right)$ & 3F & 5F \\
Control primers & GGTGGATGCAACAGGGAAAGGTGG & CTGCTATGCGTCCCCCTTTGCAGG \\
& 3R & 5R \\
& CCAAAGGCTGGAAAGCTCTGAGACC & GTCTTAGGGACAAAGCAGCGCTGGG \\
\hline Allele-specific primers & 9F & 5R \\
& GAACACGGAGGCAAGGCGTG & GTCTTAGGGACAAAGCAGCGCTGGG \\
& 9Rmut & 5Fmut \\
& AGCTGCACGGGGTGGTACAA & GGCTGCTTGTGTGTTTCAGGTGCC \\
& 9Rwt & 5Fwt \\
\hline Size of control product & AGCTGCACGGGGTGGTACAC & GGCTGCTTGTGTGTTTCAGGTGCT \\
\hline Size of allele-specific product & 241 bp & 252 bp \\
\hline
\end{tabular}


used. Serum 7DHC and 8DHC levels were quantified by GC/ MS. In our clinical laboratory we performed GC/MS analysis in eleven SLOS patients. As expected, most of the patients had abnormally reduced levels of cholesterol measured by GC/MS and all patients with SLOS had markedly increased levels of 7DHC. The level of 7DHC varied from a low of 0.21 $\mathrm{mmol} / \mathrm{l}$ to a high of $1.19 \mathrm{mmol} / \mathrm{l}$. The cholesterol level (GC/ $\mathrm{MS}$ ) varied from $0.12 \mathrm{mmol} / \mathrm{l}$ to $1.91 \mathrm{mmol} / \mathrm{l}$. Normal level of cholesterol in children younger than 2 years was $2.23 \pm 0.31$ (unpublished observation). The cholesterol levels in SLOS patients measured by commercial oxidase-based assay was higher compared with serum cholesterol levels determined by GC/MS, most likely due to a false positive cross-reaction of 7DHC and 8DHC in this cholesterol oxidase based systems. All data are summarised in Table 3.

\section{Mutation analysis}

We have determined, in 17 patients with clinically and biochemically characterised SLOS, the mutational spectrum of DHCR7 gene. By direct sequencing of the coding exons of DHCR7 a total of six mutations were identified on 34 alleles: one nonsense mutation W151X (18/34) and five missense mutations V326L (8/34), L109P (3/34), G410S (2/34), R352Q (2/34), Y432C (1/34). All mutations have been already reported. The most common mutations were W151X and V326L, representing $76 \%$ of all mutations. Mutation W151X was found in 13 of 17 patients. Characteristics of the mutations are summarised in Table 4. We identified both mutations in all analysed patients. Eight different genotypes were found in patients with SLOS (Table 3). The most common genotypes were W151X/W151X

Table 3. Sex, age at diagnose, actual age, biochemical and molecular data of SLOS patients

\begin{tabular}{|l|c|c|c|c|c|c|c|}
\hline Patient & Sex & $\begin{array}{c}\text { Age at } \\
\text { diagnose }\end{array}$ & Actual age & $\begin{array}{c}\text { Chol. }(\mathrm{mmol} / \mathrm{l}) \\
\text { oxidase test }\end{array}$ & $\begin{array}{c}\text { Chol. (mmol/l) } \\
\text { GC/MS }\end{array}$ & $\begin{array}{c}\text { 7DHC } \\
\text { (mmol/l) }\end{array}$ & Genotype \\
\hline P1 & $\mathrm{M}$ & $1 \mathrm{~d}$ & $\dagger 5 \mathrm{~d}$ & 1.16 & no data & no data & $\mathrm{W} 151 \mathrm{X} / \mathrm{L} 109 \mathrm{P}$ \\
\hline P2 & $\mathrm{F}$ & newborn & $15 \mathrm{y}$ & 2.06 & 0.40 & 0.28 & $\mathrm{~L} 109 \mathrm{P} / \mathrm{L} 109 \mathrm{P}$ \\
\hline P3 & $\mathrm{M}$ & $6 \mathrm{~m}$ & no data & 1.8 & 0.47 & 0.88 & $\mathrm{~W} 151 \mathrm{X} / \mathrm{V} 326 \mathrm{~L}$ \\
\hline P4 & $\mathrm{M}$ & $7 \mathrm{~d}$ & $\dagger 1 \mathrm{~m}$ & 0.92 & 0.12 & 1.16 & $\mathrm{~W} 151 \mathrm{X} / \mathrm{W} 151 \mathrm{X}$ \\
\hline P5 & $\mathrm{M}$ & newborn & $\dagger 21 \mathrm{~d}$ & 1.15 & 0.91 & 0.83 & $\mathrm{~W} 151 \mathrm{X} / \mathrm{W} 151 \mathrm{X}$ \\
\hline P6 & $\mathrm{M}$ & newborn & $\dagger 25 \mathrm{~d}$ & 0.42 & 0.12 & 0.7 & $\mathrm{~W} 151 \mathrm{X} / \mathrm{W} 151 \mathrm{X}$ \\
\hline P7 & $\mathrm{F}$ & $8 \mathrm{~m}$ & $24 \mathrm{y}$ & 2.13 & 1.05 & 0.21 & $\mathrm{~V} 326 \mathrm{~L} / \mathrm{V} 326 \mathrm{~L}$ \\
\hline P8 & $\mathrm{F}$ & $9 \mathrm{~d}$ & $\dagger 44 \mathrm{~d}$ & 1.13 & 0.34 & 0.45 & $\mathrm{~W} 151 \mathrm{X} / \mathrm{V} 326 \mathrm{~L}$ \\
\hline P9 & $\mathrm{F}$ & $11 \mathrm{y}$ & $14 \mathrm{y}$ & 1.98 & 1.91 & 1.19 & $\mathrm{~W} 151 \mathrm{X} / \mathrm{V} 326 \mathrm{~L}$ \\
\hline P10 & $\mathrm{F}$ & $2 \mathrm{y}$ & $\dagger$ & 0.74 & 0.18 & 0.76 & $\mathrm{~W} 151 \mathrm{X} / \mathrm{G} 410 \mathrm{~S}$ \\
\hline P11 & $\mathrm{M}$ & $3 \mathrm{~m}$ & $4 \mathrm{y}$ & 1.47 & 1.32 & 0.43 & $\mathrm{~V} 326 \mathrm{~L} / \mathrm{V} 326 \mathrm{~L}$ \\
\hline P12 & $\mathrm{M}$ & newborn & $\dagger$ newborn & 1.53 & no data & no data & $\mathrm{W} 151 \mathrm{X} / \mathrm{V} 326 \mathrm{~L}$ \\
\hline P13 & F & $14 \mathrm{y}$ & $14 \mathrm{y}$ & no data & 1.8 & 0.71 & $\mathrm{~W} 151 \mathrm{X} / \mathrm{Y} 432 \mathrm{C}$ \\
\hline P14 & $\mathrm{M}$ & newborn & $\dagger 26 \mathrm{~d}$ & no data & no data & no data & $\mathrm{W} 151 \mathrm{X} / \mathrm{G} 410 \mathrm{~S}$ \\
\hline P15 & F & newborn & $\dagger 5 \mathrm{w}$ & no data & no data & no data & $\mathrm{W} 151 \mathrm{X} / \mathrm{W} 151 \mathrm{X}$ \\
\hline P16 & F & newborn & $\dagger 13 \mathrm{w}$ & no data & no data & no data & $\mathrm{W} 151 \mathrm{X} / \mathrm{R} 352 \mathrm{Q}$ \\
\hline P17 & F & no data & no data & no data & no data & no data & W151X/R352Q \\
\hline
\end{tabular}

Chol., cholesterol; 7DHC, 7-dehydrocholesterol; † exitus; GC/MS, gas chromatography/mass spectrometry; d, day; w, week; m, month; y, year.

Table 4. DHCR7 mutations in Slovak patients with SLOS

\begin{tabular}{|l|c|c|c|c|c|c|}
\hline Mutation & Exon & Nt substitution & Aa exchange & Mutation type & Protein domain $^{\text {a }}$ & Conserved aa $^{\mathrm{b}}$ \\
\hline L109P & 5 & $326 \mathrm{~T}>\mathrm{C}$ & Leu $\rightarrow$ Pro & missense & TM2 & yes \\
\hline W151X & 6 & $452 \mathrm{G}>\mathrm{A}$ & Trp $\rightarrow$ stop & nonsense & - & no \\
\hline V326L & 9 & $976 \mathrm{G}>$ T & Val $\rightarrow$ Leu & missense & TM7 & yes \\
\hline R352Q & 9 & $1055 G>A$ & Arg $\rightarrow$ Gln & missense & TM8 & yes \\
\hline G410S & 9 & $1228 G>A$ & Gly $\rightarrow$ Ser & missense & 4 CL & yes \\
\hline Y432C & 9 & $1289 A>G$ & Tyr $\rightarrow$ Cys & missense & TM9 & yes \\
\hline
\end{tabular}

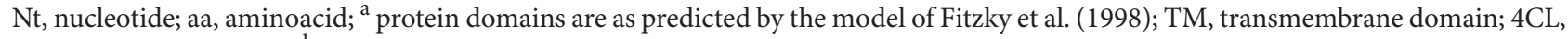
fourth cytoplasmic loop; ${ }^{\mathrm{b}}$ conserved amino acids as defined by Correa-Cerro and Porter (2005). 
A

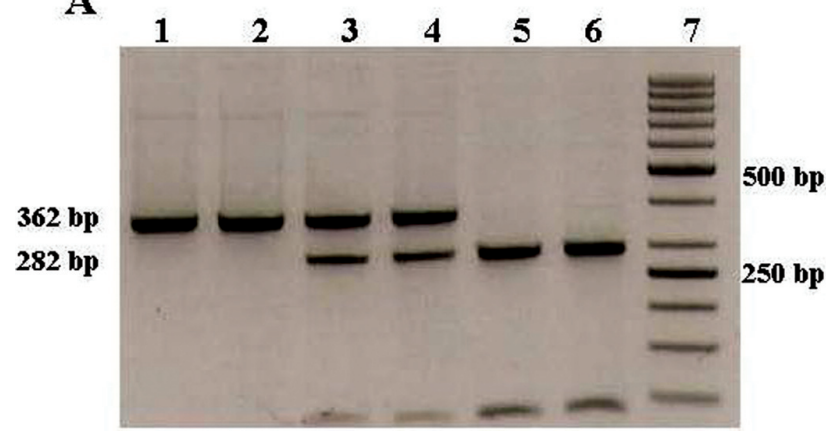

$\mathbf{C}$ 1

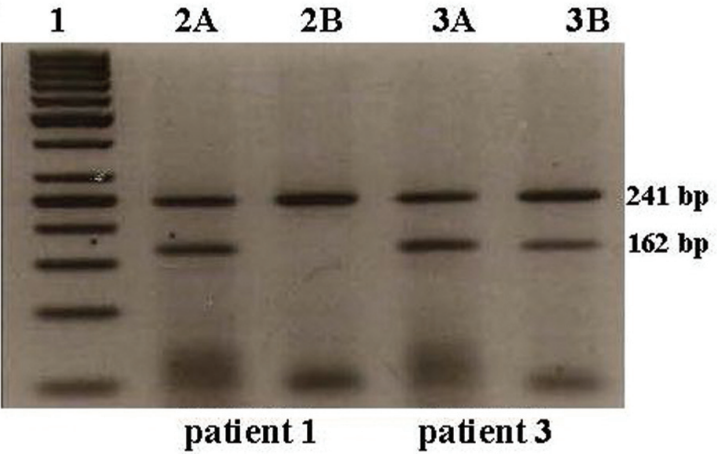

B
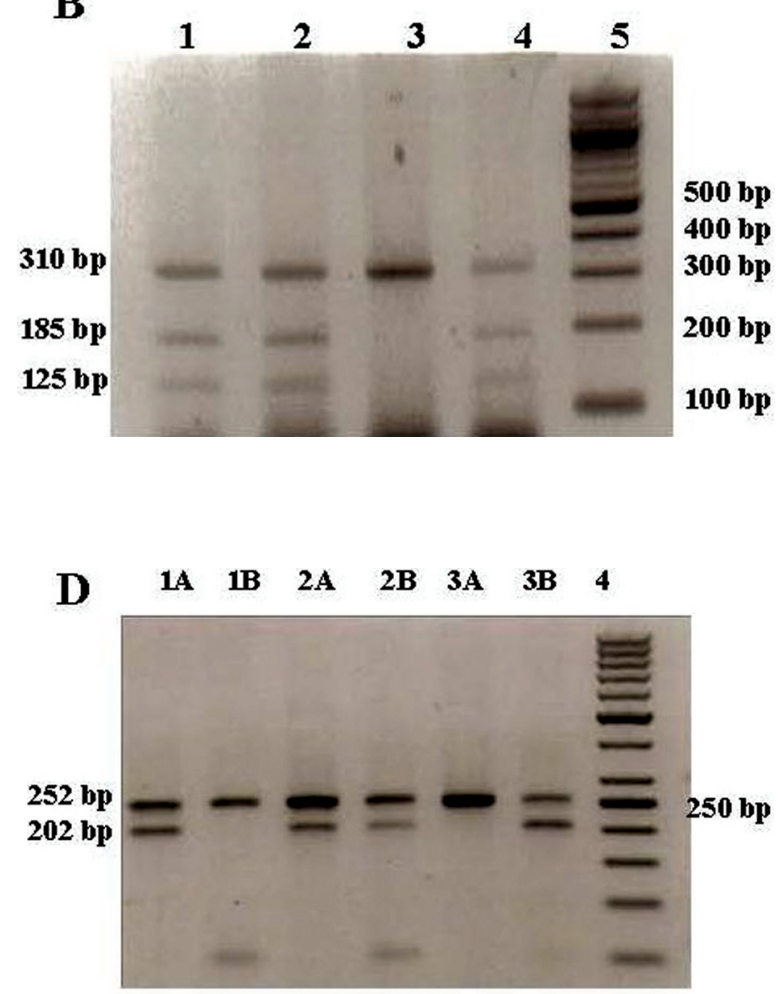

patient 13 patient 1 patient 2

Figure 1. Demonstration of PCR-RFLP assays. A. PCR-RFLP of mutation W151X in exon 6 by AluI. The wild type allele is not susceptible to AluI restriction enzyme digestion and remains undigested (362 bp). The presence of W151X mutation creates an AluI restriction site. The digested mutant allele gives rise to $282 \mathrm{bp}$ and $80 \mathrm{bp}$ (poor visible) restriction fragments. Lanes 1 and 2 show healthy individuals (homozygous for wild type allele; single uncut fragment $362 \mathrm{bp}$ ), in lanes 3 and 4 are SLOS patients compound heterozygous for mutation W151X (patient 1 and 3; combination of $362 \mathrm{bp}+282 \mathrm{bp}+80 \mathrm{bp}$ product sizes), in lanes 5 and 6 are shown W151X homozygous SLOS patients (patient 5 and 6; $282 \mathrm{bp}+80 \mathrm{bp}$ restriction fragments), lane 7 shows $50 \mathrm{bp}$ DNA ladder. B. PCR-RFLP of mutation Y432C in exon 9 by $\mathrm{HpyCH} 4 \mathrm{~V}$. The wild type allele is not susceptible to $\mathrm{HpyCH} 4 \mathrm{~V}$ digestion and remains undigested ( $310 \mathrm{bp}$ ). The presence of Y432C mutation creates the recognition site for restriction enzyme $\mathrm{HpyCH} 4 \mathrm{~V}$. The digested mutant allele gives rise to $185 \mathrm{bp}$ and $125 \mathrm{bp}$ restriction fragments. In lanes 1, 2 and 4 are shown Y432C heterozygous patients (lane 1: patient 13, lane 2: mother of patient 13, lane 4: sister of patient 13; combination of $310 \mathrm{bp}+185 \mathrm{bp}+185 \mathrm{bp}$ product sizes), in lane 3 is healthy individual, father of patient 13 (310 bp uncut fragment), lane 5: $100 \mathrm{bp}$ DNA ladder. C. Detection of mutation V326L by ARMS assay. ARMS test for each patient consists of two complementary reactions. One contains primers for amplification of wild type allele (lanes A) and the other one contains primers for amplification of mutant allele (lanes B). Both reactions contain control primers. Allele specific primers amplify a $162 \mathrm{bp}$ product and control primers amplify a $241 \mathrm{bp}$ product, which serves as an internal positive control of PCR amplification. Patient 1 (lanes 2A and 2B): homozygous for wild type allele. 162 bp PCR product is present only in reaction for wild type allele amplification (lane 2A). Patient 3: heterozygous for V326L mutation. 162 bp PCR products are present in both reactions (lanes 3A and 3B). D. Detection of mutation L109P by ARMS assay. Wild type allele amplification are in lanes A and mutant allele amplification are in lanes B. Allele specific primers amplify a 202 bp product and control primers amplify a 252 bp product. Patient 13 (lanes 1A and 1B): homozygous for wild type allele. 202 bp PCR product is present only in reaction for wild type allele amplification (lane 1A). Patient 2: homozygous for mutation L109P. 202 bp PCR product is present only in reaction for mutant allele amplification (lane 3B). Patient 1: heterozygous for L109P mutation. 202 bp PCR products are present in both reactions (lanes 2A and 2B).

(4 of 17 patients) and W151X/V326L (4 of 17 patients). Four W151X homozygotes, two V326L homozygotes and one L109P homozygote were identified. Both parents if samples were available underwent DHCR7 mutation analysis to confirm the segregation of mutation. Also five previously described silent mutations - neutral polymorphisms were identified: Q63Q,
T69T in exon 4, N146N in exon 6 a D386D, G424G in exon 9. Five of our patient underwent mutation analysis previously in the Centre of Molecular Biology and Gene Therapy, University Hospital Brno (Kozák et al. 2000).

The newly developed PCR-based assays (RFLP and ARMS) were used in patients who manifested elevated levels 
of 7DHC to screen the most common mutations (Figure 1). Compared with direct sequencing PCR-based assays are rapid, cost-effective and straightforward.

\section{Discussion}

The biochemical abnormalities of SLOS allow an accurate and rapid diagnosis using GC/MS analysis of plasma sterols. The detection of increased levels of 7DHC and 8DHC in body fluids and tissues is highly specific for SLOS and usually serves as the very effective laboratory test to confirm a clinical suspicion. The biochemical profile of SLOS reveals a continuum of both 7DHC and cholesterol levels. Serum $7 \mathrm{DHC}$ levels range from 10- to over 1000-fold greater than normal (in normal plasma 7DHC is present only in trace amounts). SLOS is frequently associated with reduced levels of cholesterol but about $10 \%$ of affected patients have normal cholesterol level (Tint et al. 1994; Cunniff et al. 1997). In this study, all patients manifested elevated levels of 7DHC and decreased levels of cholesterol. Concentration of total serum cholesterol was quantified using GC/MS method and oxidase-based assay. Cholesterol levels in SLOS patients measured by oxidase-based assay were significantly higher than serum cholesterol levels measured by GC/MS, probably due to a cross-reaction of 7DHC and 8DHC in the cholesterol oxidase-based methods, leading to a false elevation of cholesterol level (Kelley and Hennekam 2000).

Using direct sequencing and PCR-based assays we achieved identification of 6 different mutations in 17 families. The highest allele frequency was observed for the nonsense mutation W151X in exon 6 (53\%, 18/34 alleles). This mutation firstly described by Fitzky et al. (1998) creates a stop codon and causes premature translation termination. This nonsense mutation represents non-functional null allele and results in complete loss of enzymatic activity of DHCR7. Nonsense mediated mRNA decay may be the major mechanism resulting in loss of enzymatic activity (Witsch-Baumgartner et al. 2001a,b). However, if the enzyme is synthesised only with its amino terminal half (without the highly conserved carboxyl terminus), it seems to be non-functional. We also identified 5 different missense mutations: V326L (23.5\%, 8/34), L109P (8.8\%, 3/34), R352Q (5.9\%, 2/34), G410S (5.9\%, $2 / 34)$ and Y432C $(2.9 \%, 1 / 34)$. Majority of the identified missense mutation (V326L, L109P, R352Q, and Y432C) are localised in the transmembrane domains of the protein and affect the protein stability. One of the missense mutations (G410S) is localised in the fourth cytoplasmic loop. This region was suggested to bind $\mathrm{NADPH}$, the cofactor of 7DHC conversion (Fitzky et al. 1999). The detected missense mutations affect amino acid residues that are conserved between plants and vertebrate enzymes, suggesting that these sites are critical for the protein function.
W151X is the most common mutation in Slovak patients with SLOS. We identified four W151X homozygotes (there was no consanguinity in SLOS families) and another 9 patients who were compound heterozygotes for W151X allele. This fact indicates a high frequency of W151X carriers in Slovak population. The W151X carrier frequency (based on newborn screening) in Poland was estimated as $1.8 \%$ (Ciara et al. 2006). We also found three V326L and one L109P homozygotes. There were no compound heterozygotes without a W151X allele. We also found a rare Y432C mutation which was identified in one patient. Y432C was firstly described by Witsch-Baumgartner et al. (2005) in a compound heterozygous patient from Germany. Only this two mutated alleles are reported up to date. We developed the PCR-RFLP-based assay for Y432C mutation to verify the sequencing data and enhance the mutation analysis in this family. DNA samples from patient's relatives were available and carrier status of this mutation was identified in mother and sister (Figure 1B).

Mutations W151X and V326L accounted for 76\% of all mutated alleles in our study. In the world-wide mutation database of the DHCR7 gene W151X is the third (5.7\%) and V326L the fourth (4.8\%) most common mutation (Yu and Patel 2005). The other identified mutations in this study are less common. The Slovak mutational spectrum is different from those seen in patients from Western, Southern and Northern European populations and North America and is similar to that observed in other Central European countries. Mutation W151X and V326L are very frequent among the Polish patients (32.4 and 27.9\%, respectively) and Czech patients (50 and $27.8 \%$, respectively), intermediate frequency was observed in Germany and Austria (18\% for each) and have a low frequency in the UK, USA, Canada, Sweden, Italy, Spain and Portugal (Kozák et al. 2000; Witsch-Baumgartner et al. 2001a, 2005; Ciara et al. 2004; Cardoso et al. 2005). The splice-site mutation IVS8-1G>C is the most common in patients from North and West Europe and North America. Mutation T93M is very frequent in South European countries (Witsch-Baumgartner et al. 2001a, 2005; Cardoso et al. 2005).

This is the first study presenting the biochemical and molecular basis of Slovak patients with SLOS. Our results contribute to broaden mutation spectrum of DHCR7 gene among European countries. We also supply data about the mutations in Central European region.

In our experience, sequence analysis of the DHCR7 coding region has a sensitivity of detection that approaches $100 \%$. Also we developed rapid, simple, cost-effective and highly specific PCR-based assays to screen the common mutations. The four presented PCR-based assays allowed the identification of $88.2 \%$ mutated alleles in Slovak patients and facilitate identification of mutations in future cases. Obviously, in cases of negative results, a complete gene sequence analysis should 
be used. These assays provide a rapid method that might be used in population studies for carrier testing. Allele specific assays and restriction analyses are useful for populations that have limited numbers of common mutations. Molecular analysis of the DHCR7 gene opens the possibility of diagnosing SLOS patients with very mild signs and borderline biochemical results but also retrospective diagnosis of severe perinatal lethal cases when insufficient biological material for biochemical analysis is available and offers the options for prenatal diagnosis, too (Witsch-Baumgartner et al. 2001b).

Acknowledgments. We are grateful to all the clinicians from different Slovak hospitals whose contribution made the present study possible: Jana Behunová, Martin Mistrík, Janka Barošová, Eva Véghová, František Cisárik, Dana Kantarská. We also thank to Centre of Molecular Biology and Gene Therapy, University Hospital Brno, Czech Republic for cooperation.

\section{References}

Cardoso M. L., Balreira A., Martins E., Nunes L., Cabral A., Marques M., Lima M. R, Marques J. S, Medeira A., Cordeiro I., Pedro S., Mota M. C., Dionisi-Vici C., Santorelli F. M., Jakobs C., Clayton P. T., Vilarinho L. (2005): Molecular studies in Portuguese patients with Smith-Lemli-Opitz syndrome and report of three new mutations in DHCR7. Mol. Genet. Metab. 85, 228-235

Ciara E., Nowaczyk M. J., Witsch-Baumgartner M., Malunowicz E., Popowska E., Jezela-Stanek A., Piotrowicz M., Waye J. S., Utermann G., Krajewska-Walasek M. (2004): DHCR7 mutations and genotype-phenotype correlation in 37 Polish patients with Smith-Lemli-Opitz syndrome. Clin. Genet. 66, 517-524

Ciara E., Popowska E., Piekutowska-Abramczuk D., Jurkiewicz D., Borucka-Mankiewicz M., Kowalski P., Goryluk-Kozakiewicz B., Nowaczyk M. J., Krajewska-Walasek M. (2006): SLOS carrier frequency in Poland as determined by screening for Trp151X and Val326Leu DHCR7 mutations. Eur. J. Med. Genet. 49, 499-504

Correa-Cerro L. S., Porter F. D. (2005): 3beta-hydroxysterol delta7-reductase and the Smith-Lemli-Opitz syndrome. Mol. Genet. Metab. 84, 112-126

Cunniff C., Kratz L. E., Moser A., Natowicz M. R., Kelley R. I. (1997): Clinical and biochemical spectrum of patients with RSH/ Smith-Lemli-Opitz syndrome and abnormal cholesterol metabolism. Am. J. Med. Genet. 68, 263-269

Fitzky B. U., Witsch-Baumgartner M., Erdel M., Lee J. N., Paik Y. K., Glossmann H., Utermann G., Moebius F. F. (1998): Mutations in the delta7-sterol reductase gene in patients with the Smith-Lemli-Opitz syndrome. Proc. Natl. Acad. Sci. U.S.A. 95, 8181-8186

Fitzky B. U., Glossmann H., Utermann G., Moebius F. F. (1999): Molecular genetics of the Smith-Lemli-Opitz syndrome and postsqualene sterol metabolism. Curr. Opin. Lipidol. 10, 123-131
Irons M., Elias E. R., Salen G., Tint G. S., Batta A. K. (1993): Defective cholesterol biosynthesis in Smith-Lemli-Opitz syndrome. Lancet 341, 1414

Kelley R. I. (1995): Diagnosis of Smith-Lemli-Opitz syndrome by gas chromatography/mass spectrometry of 7-dehydrocholesterol in plasma, amniotic fluid and cultured skin fibroblasts. Clin. Chim. Acta 236, 45-58

Kelley R. I. (1998): RSH/Smith-Lemli-Opitz syndrome: mutations and metabolic morphogenesis. Am. J. Hum. Genet. 63, 322-326

Kelley R. I., Hennekam R. C. (2000): The Smith-Lemli-Opitz syndrome. J. Med. Genet. 37, 321-335

Kozák L., Francová H., Hrabincová E., Procházková D., Jüttnerová V., Bzdúch V., Šimek P. (2000): Smith-Lemli-Opitz syndrome: molecular-genetic analysis of ten families. J. Inherit. Metab. Dis. 23, 409-412

Moebius F. F., Fitzky B. U., Lee J. N., Paik Y. K., Glossmann H. (1998): Molecular cloning and expression of the human 87-sterol reductase. Proc. Natl. Acad. Sci. U.S.A. 95, 1899-1902

Nowaczyk M. J., Nakamura L. M., Eng B., Porter F. D., Waye J. S. (2001): Frequency and ethnic distribution of the common DHCR7 mutation in Smith-Lemli-Opitz syndrome. Am. J. Med. Genet. 102, 383-386

Nowaczyk M. J., Waye J. S. (2001): The Smith-Lemli-Opitz syndrome: a novel metabolic way of understanding developmental biology, embryogenesis, and dysmorphology. Clin. Genet. 59, 375-386

Opitz J. M. (1994): RSH/SLO (“Smith-Lemli-Opitz”) syndrome: historical, genetic, and developmental considerations. Am. J. Med. Genet. 50, 344-346

Opitz J. M. (1999): RSH (so-called Smith-Lemli-Opitz) syndrome. Curr. Opin. Pediatr. 11, 353-362

Ryan A. K., Bartlett K., Clayton P., Eaton S., Mills L., Donnai D., Winter R. M., Burn J. (1998): Smith-Lemli-Opitz syndrome: a variable clinical and biochemical phenotype. J. Med. Genet. 35, 558-565

Tint G. S., Irons M., Elias E. R., Batta A. K., Frieden R., Chen T. S., Salen G. (1994): Defective cholesterol biosynthesis associated with the Smith-Lemli-Opitz syndrome. N. Engl. J. Med. 330, 107-113

Tint G. S., Seller M., Hughes-Benzie R., Batta A. K., Shefer S., Genest D., Irons M., Elias E., Salen G. (1995): Markedly increased tissue concentrations of 7-dehydrocholesterol combined with low levels of cholesterol are characteristic of the Smith-Lemli-Opitz syndrome. J. Lipid Res. 36, 89-95

Wassif C. A., Maslen C., Kachilele-Linjewile S., Lin D., Linck L. M., Connor W. E., Steiner R. D., Porter F. D. (1998): Mutations in the human sterol delta7-reductase gene at 11q12-13 cause Smith-Lemli-Opitz syndrome. Am. J. Hum. Genet. 63, 55-62

Waterham H. R., Wijburg F. A., Hennekam R. C., Vreken P., PollThe B. T., Dorland L., Duran M., Jira P. E., Smeitink J. A., Wevers R. A., Wanders R. J. (1998): Smith-Lemli-Opitz syndrome is caused by mutations in the 7-dehydrocholesterol reductase gene. Am. J. Hum. Genet. 63, 329-338

Witsch-Baumgartner M., Ciara E., Loffler J., Menzel H. J., Seedorf U., Burn J., Gillessen-Kaesbach G., Hoffmann G. F., Fitzky 
B. U., Mundy H., Clayton P., Kelley R. I., KrajewskaWalasek M., Utermann G. (2001a): Frequency gradients of DHCR7 mutations in patients with Smith-Lemli-Opitz syndrome in Europe: evidence for different origins of common mutations. Eur. J. Hum. Genet. 9, 45-50

Witsch-Baumgartner M., Loffler J., Utermann G. (2001b): Mutations in the human DHCR7 gene. Hum. Mutat. 17, $172-182$

Witsch-Baumgartner M., Clayton P., Clusellas N., Haas D., Kelley R. I., Krajewska-Walasek M., Lechner S., Rossi M., Zschocke J.,
Utermann G. (2005): Identification of 14 novel mutations in DHCR7 causing the Smith-Lemli-Opitz syndrome and delineation of the DHCR7 mutational spectra in Spain and Italy. Hum. Mutat. 25, 412

Yu H., Patel S. B. (2005): Recent insights into the Smith-Lemli-Opitz syndrome. Clin. Genet. 68, 383-391

Received: August 6, 2008

Final version accepted: October 3, 2008 